\title{
Using ground based radar interferometry during emergency: the case of the A3 motorway (Calabria Region, Italy) threatened by a landslide
}

\author{
C. Del Ventisette ${ }^{1}$, E. Intrieri ${ }^{1}$, G. Luzi ${ }^{1}{ }^{*}$, N. Casagli ${ }^{1}$, R. Fanti ${ }^{1}$, and D. Leva ${ }^{2}$ \\ ${ }^{1}$ Department of Earth Sciences, University of Firenze, Firenze, Italy \\ ${ }^{2}$ Ellegi s.r.l. - LisaLab, Legnano (MI), Italy \\ *now at: Institut de Geomàtica, Barcelona, Spain
}

Received: 23 May 2011 - Revised: 29 July 2011 - Accepted: 8 August 2011 - Published: 22 September 2011

\begin{abstract}
The rapid assessment of the evolution of the phenomena which occur during an emergency, along with an all weather and h24 monitoring capability, are probably the main characteristics of a system aimed at optimizing intervention in natural disasters, such as landslide collapses. A few techniques are able to provide all these features remotely, hence assuring safe conditions to operators. This paper reports on an application of the GB-InSAR (Ground-Based Interferometric Synthetic Aperture Radar) technique to monitor a landslide threatening an infrastructure, the A3 motorway in the Calabria Region (Southern Italy), in emergency conditions. Here, it is evaluated how well this technique is able to satisfy these requirements. On 30 January 2009, a mass movement never detected before and located near Santa Trada viaduct caused the closure of that sector of the A3 motorway. The prompt installation of a GB-InSAR permitted to follow and to understand the temporal evolution of the landslide until the end of the emergency and then safely reopen of the motorway. The main steps of the GB-InSAR interferometry data interpretation used in managing this emergency are described and discussed here. In detail, data collected through a continuous acquisition have permitted the division of the unstable area into three smaller zones characterized by different extents of displacement.
\end{abstract}

\section{Introduction}

In managing hydrogeological emergencies, a system able to ensure a continuous remote monitoring is of fundamental importance. The capability to collect data in almost every meteorological condition makes spaceborne synthetic aperture

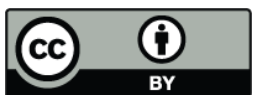

Correspondence to: C. Del Ventisette (chiara.delventisette@unifi.it) radar interferometry (InSAR) a powerful tool, but due to the long revisiting time of the majority of the spaceborne SAR missions, of the order of weeks, it cannot perform a continuous monitoring. On the other hand, in the last years, GBInSAR has proven to be a reliable remote sensing tool which enhances the advantages of the spaceborne InSAR and provides displacement maps with high spatial and temporal resolutions and accuracy (Antonello et al., 2004; Atzeni et al., 2001a; Barbieri et al., 2004; Barla et al., 2010; Casagli et al., 2009; Luzi et al., 2006; Pieraccini et al., 2003; Rudolf et al., 1999; Tarchi et al., 1997, 1998, 1999, 2000a). In particular, its high acquisition frequency (up to one image every 6-7 min) and a rapid deployment make it a promising tool for managing local (at single slope scale) emergencies.

Landslide monitoring applications through GB-InSAR have been consolidated in the last years by several research teams who have tested the consistency of this technique in different situations (Antonello et al., 2008; Atzeni et al., 2001b; Casagli et al., 2010; Gigli et al., 2011; Luzi et al., 2004; Pieraccini et al., 2000a). In the best conditions, i.e. when a good correlation is preserved among the observed electromagnetic scenarios over the analyzed temporal baseline, millimeter accuracy on surface motion and deformation can be exploited.

In this paper an application of the GB-InSAR technique to monitor a landslide threatening infrastructures in an emergency situation is presented. In this case, the main endangered infrastructure is a motorway, namely the A3 branch located in the Calabria Region (Southern Italy). During December 2008 and January 2009 intense rainfall occurred in Italy, especially in the southern regions. Cumulative monthly rain values of $146.0 \mathrm{~mm}$ and $188.6 \mathrm{~mm}$ were measured respectively in December 2008 and January 2009 by the rain gauge installed near Scilla (Reggio Calabria - Calabria Region), located close to the study area; these values are largely over the seasonal average and caused the saturation of soils

Published by Copernicus Publications on behalf of the European Geosciences Union. 


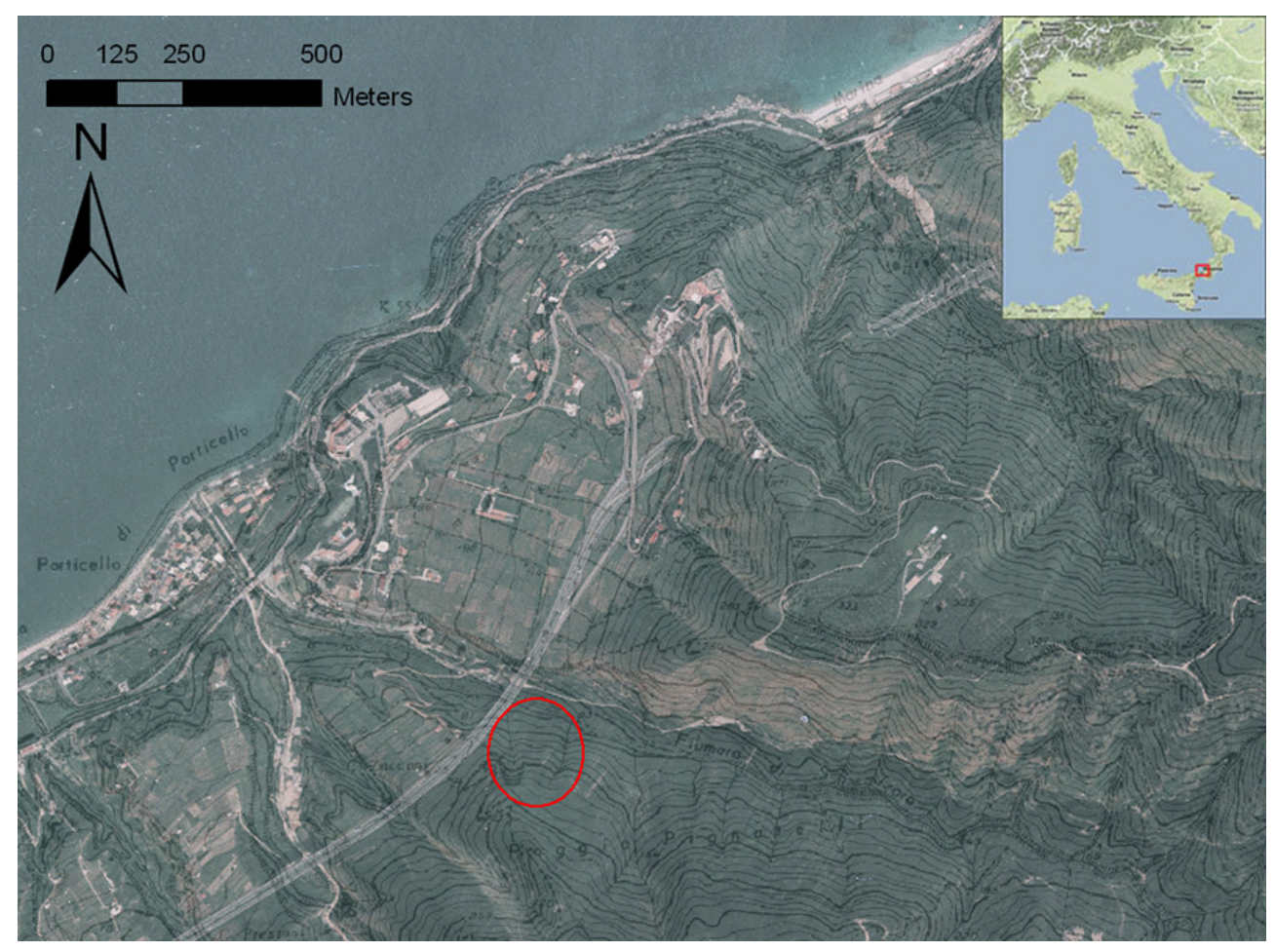

Fig. 1. Geographical setting of Santa Trada landslide (Volo Italia, 2000).

for almost the entire period, worsening the already critical hydrogeological conditions. On 30 January 2009 a mass movement never detected before and located near Santa Trada viaduct caused the closure of that sector of the A3 motorway in an area already affected by other landslides, causing further economic losses.

Sequences of deformation maps provided by a GB-InSAR can allow us to study the landslide's temporal evolution, even when the acceleration changes are very small, and to evaluate the volume of the material involved in the mass movement. In addition, although data are few, an integration of landslide movements with the available rainfall data has been tentatively made to make an approximate assessment on the influence of rainfall on the activity of the landslide. This information is of primary importance, especially in the first phase of the emergency management, for an accurate assessment of upcoming risk scenarios necessary to draw up the emergency plans for civil protection purposes.

\section{Test-site description}

A landslide, here named Santa Trada after the name of the nearest stream called Fiumara di Santa Trada, developed on 30 January close to Villa San Giovanni municipality (Fig. 1). Since neither previous record nor historical data of this landslide are available, it is not possible to classify it as a new landslide or a reactivated one. However, in the official maps of the "Hydrogeological Setting Plan" (PAI - Piano di Assetto Idrogeologico) and of the "Inventory of landslides in Italy" (IFFI - Inventario dei Fenomeni Franosi in Italia) several landslides landslide have been mapped in this area.

It involved a sector of the main communication route (A3 motorway; Fig. 2) and for this reason the Department of Civil Protection (DPC) decided to install a monitoring system for early warning purposes.

From a geological point of view, this area is characterized by Paleozoic micaschists and augen gneiss overlaid by weathered Paleozoic biotite and muscovite granites along with arkosic Pleistocenic sands and conglomerates (Marchetti, 1968). These are involved in the mass movement.

Santa Trada basin is surrounded by reliefs approximately below $700 \mathrm{~m}$ a.s.l. on the right side of the stream, and $600 \mathrm{~m}$ a.s.l. on the left side. The slope involved by the landslide has an inclination of $25^{\circ}-30^{\circ}$ upslope which increases up to $40^{\circ}$ downslope. The landslide is about $100 \mathrm{~m}$ high and has a maximum width of about $90 \mathrm{~m}$. It is delimited by a fracture whose widening during the first days of monitoring was evident also through a visual inspection. Photographs of its evolution starting from 1 February until 12 March are shown in Fig. 3. The geomorphology of the landslide and recent geological field survey confirm that it is a planar slide whose thickness is estimated to be between 3 and $5 \mathrm{~m}$. A second fracture, which did not show any further deformation, is located above. 


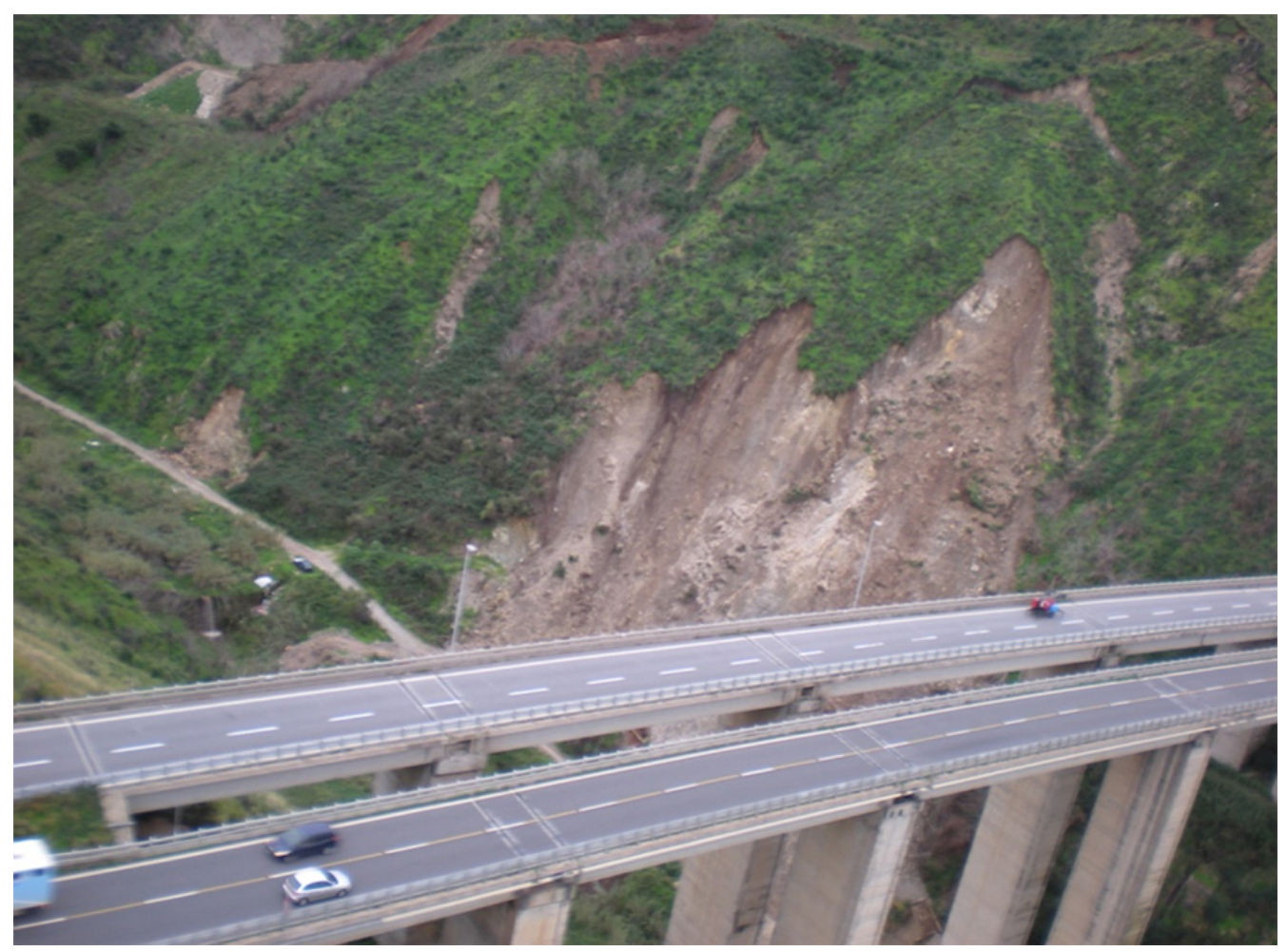

Fig. 2. Picture of Santa Trada landslide nearby the viaduct of the A3 motorway.

Although the landslide does not threaten the roadway directly, its complete collapse would hit the pillars of the Santa Trada viaduct. In the worst possible scenario, heavy rainfall could transform the slide into a debris flow which could converge on the Fiumara di Santa Trada and reach the nearby town of Porticello.

The landslide occurred on 30 January. On 31 January a GB-InSAR system was installed and, after the test phase, on 1 February, just $48 \mathrm{~h}$ after the occurrence of the landslide, the monitoring campaign started. On the basis of the GB-InSAR monitoring results and field survey, the A3 motorway, previously closed, was already partially re-opened on 2 February. The opening of the A3 motorway has been particularly significant considering that the by-pass constituted by the state road SS18 and other 28 provincial roads in the same area had been closed due to similar events. The campaign lasted until 24 April when the emergency phase was declared finished.

\section{The GB-InSAR technique}

The radar apparatus used to acquire GB-InSAR images, to perform interferometric measurements and to derive displacement maps was installed in front of the slope, on the motorway (Fig. 4). Interferograms were obtained using pairs of averaged sequential images. The working principle consists in the evaluation of the phase difference (interferomet- ric phase) pixel by pixel that occurs between the two acquisitions of complex SAR images, containing amplitude and phase information of the received echoes, at different times but in the same scenario.

The interferogram does not contain topographic information, since the position of the antennas remains the same during different scans (zero baseline condition). Through the phase difference of the backscattered signal in different times, it is possible to estimate the displacement.

Power image is related to the amplitude of the backscattered GBInSAR signal. Although the power image is not directly related to the displacement measurement, it allows us to understand the main features of the radar image and to find good points for interferometric processing. The coherence and hence the quality of the interferometric phase of the observed points is strongly related to the signal to noise ratio, i.e to the amplitude of the backscattered signal.

Considering that radar interferometry provides only the displacement component along the radar line of sight (LOS), the viewpoint of the radar was selected so that its LOS was as parallel as possible to the expected direction of the landslide motion.

The GB-InSAR, implemented by the Ellegi-LiSALab s.r.l. company, is composed of a continuous-wave step-frequency (CW-SF) transceiver, a $2.0 \mathrm{~m}$ long linear rail and two antennas that move on it at steps of few $\mathrm{mm}$, therefore permitting the realization of synthetic aperture. The microwave 

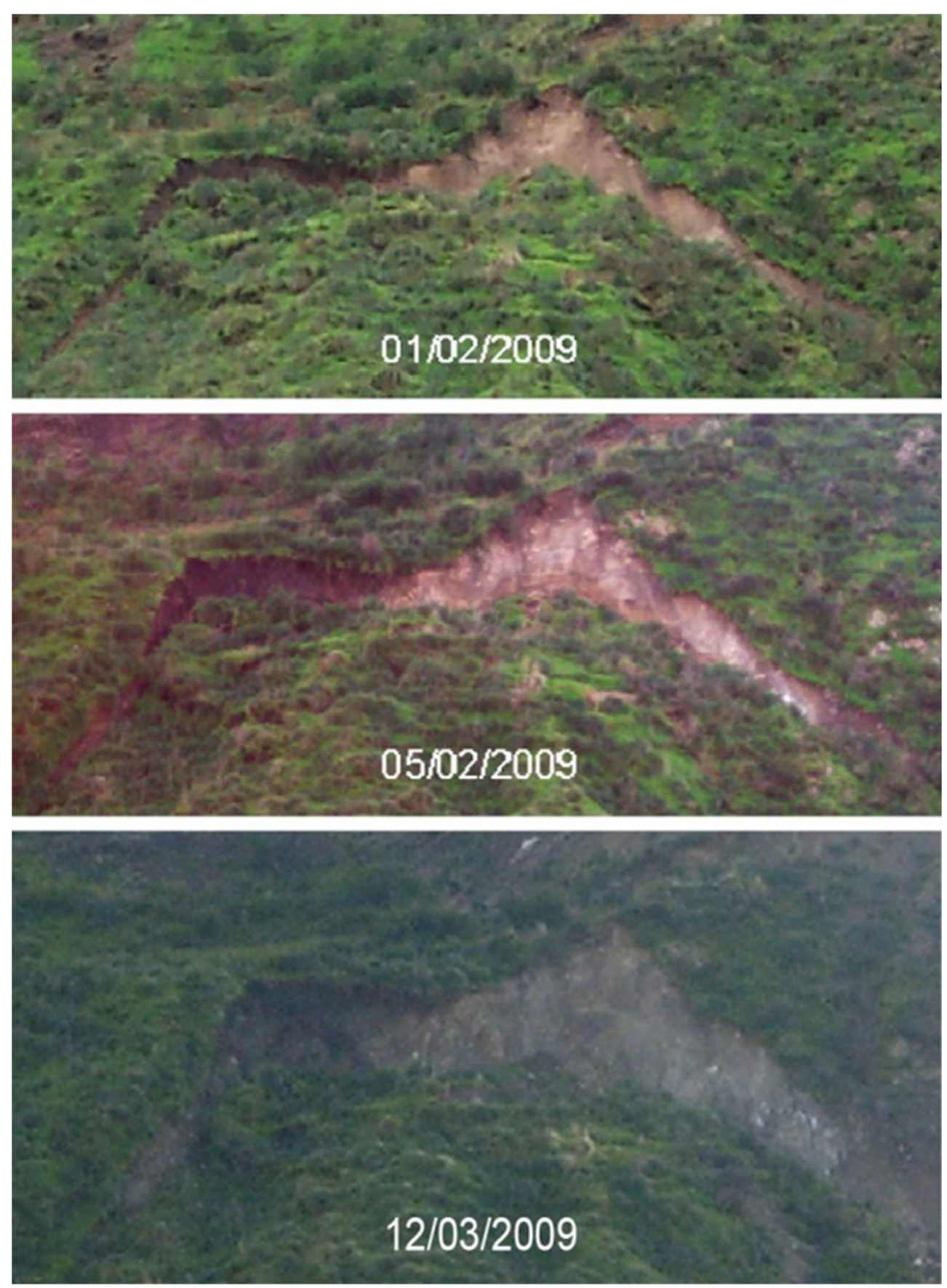

Fig. 3. Pictures of a fracture placed above the landslide. The widening of the fracture with time is clearly visible.

transmitter produces, step-by-step, continuous waves at discrete frequency values, sweeping the bandwidth from 17.0 to $17.2 \mathrm{GHz}$ (Ku band). The receiver acquires the in-phase and the quadrature components of the microwave signal backscattered by the target, thus providing its amplitude and phase. Range and cross-range synthesis of complex images is obtained by coherently summing signal contributions relative to different antenna positions and different microwave frequencies. As radar images are obtained through sampling techniques, frequency and spatial steps have to be selected in order to avoid ambiguity in range and cross-range (Tarchi et al., 2003). Selecting a sequence of images, multiple interferograms can be obtained in order to estimate the displacement component along the radar line of sight occurred during the elapsed time. The GB-InSAR image is obtained through a focalization grid such as the one depicted in Fig. 5 and the 


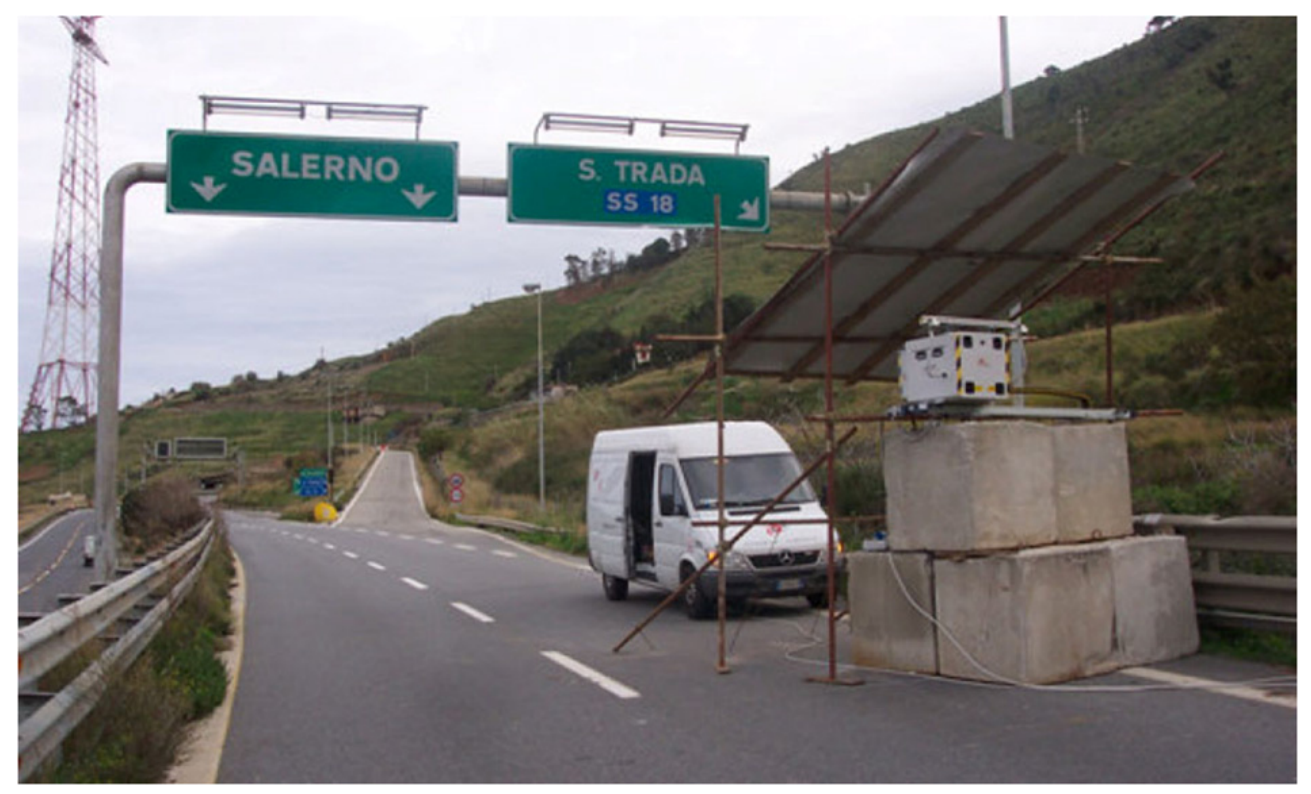

Fig. 4. Photograph of the GB-InSAR system installed on the motorway nearby Santa Trada.

Table 1. Parameters used during the Santa Trada monitoring campaign.

\begin{tabular}{ll}
\hline Central frequency & $17.1 \mathrm{GHz}$ \\
Bandwidth & $200 \mathrm{MHz}$ \\
Length of the synthetic aperture & $2 \mathrm{~m}$ \\
Minimum distance from the target & $100 \mathrm{~m}$ \\
Maximum distance from the target & $400 \mathrm{~m}$ \\
Range resolution & $0.75 \mathrm{~m}$ \\
Azimuth resolution at $100 \mathrm{~m}$ & $0.44 \mathrm{~m}$ \\
Azimuth resolution at $400 \mathrm{~m}$ & $1.75 \mathrm{~m}$ \\
\hline
\end{tabular}

final resolution of the image is related to radar parameters, as resumed in Table 1 .

Images can be acquired with a minimum of 6 min delay. Processed GB-InSAR data are sent for daily dispatching procedures aimed at monitoring the onset of deformation of the concerned area. The usefulness of the GB-InSAR system was not only limited to its capability of fully characterizing the landslide in spatial terms; it also permitted the operators to follow, during the whole campaign, the evolution of the mass movement and to study its kinematic behavior, which is fundamental in order to assess the risk scenarios' temporal evolution.

\section{The GB-InSAR results}

A photograph of the landslide, joined to the corresponding SAR power image, is represented in Fig. 6 where some letters are depicted for better comprehension. After a visual inter- pretation, necessary for overlapping radar and optical data, it was possible to obtain an overview of the actual area affected by movement and to estimate the deformation velocities. This piece of information was very important in order to roughly evaluate the magnitude of the involved material and to hypothesize the possible risk scenarios.

According to the interferometric maps collected during the campaign (Fig. 7), the unstable area has an extension of nearly $6000 \mathrm{~m}^{2}$. From this datum it is possible to estimate a total volume of about $18000-30000 \mathrm{~m}^{3}$. The obtained displacement maps also show that the landslide can be divided into 3 sectors (top sector, western sector, eastern sector; Fig. 6), characterized by different behaviors in terms of cumulative displacement and dynamics.

Two different risk scenarios were hypothesized:

- the landslide would evolve as a series of small collapses; in this case it would not probably affect the motorway pillars, even though it could block a minor road present at the foot of the slope.

- The landslide would fail as a whole. In such a case the pillars could be damaged; moreover an unstable dam on the Fiumara could be generated.

In the uppermost sector of the landslide, six representative points were selected in order to extrapolate the temporal profile of the displacement retrieved from interferometric maps (Fig. 8).

During the whole period of monitoring, several acceleration phases were clearly detectable. Between 1 February and 5 February, the average velocity of displacements along the line of sight of the instrument reached $5.5 \mathrm{~mm} \mathrm{~h}^{-1}$. The 

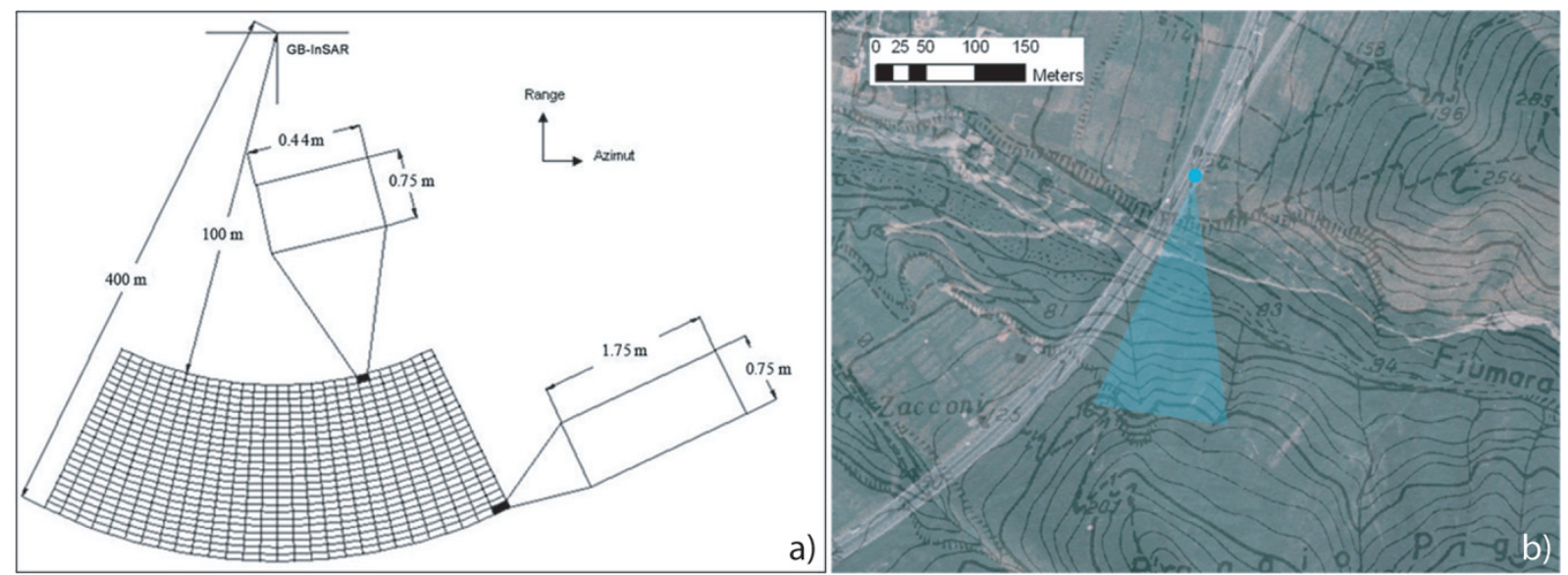

Fig. 5. (a) Resolution grid size used during the monitoring campaign of Santa Trada landslide. (b) Localization of the Santa Trada landslide nearby the A3 motorway and the Fiumara di Santa Trada. The blue area roughly represents the radar field of view.

landslide continued to accelerate until mid- February up to a value of more than $14 \mathrm{~mm} \mathrm{~h}^{-1}$. From this moment until the end of monitoring (29 April 2009), two periods of heavy acceleration overlapped to a regular decreasing of velocity; the first one occurred at the beginning of March and the second one on 21 March 2009.

During the last month an average velocity of $0.5 \mathrm{~mm} \mathrm{~h}^{-1}$ toward the radar was measured. Before the end of monitoring, the Santa Trada landslide reached a new equilibrium and the movements were low enough not to represent a risk for the infrastructures in the immediate future.

In order to understand the dynamics of the whole landslide and to highlight the difference of the three recognized sectors, cumulative displacement maps, spanning a time interval of about 7 days, were elaborated (Fig. 9).

The highest deformation was recorded during the first week after the failure, when the cumulative deformation at the top sector exceeded $800 \mathrm{~mm}$ in 7 days. The eastern sector is characterized by a cumulative deformation that reached $750 \mathrm{~mm}$. This deformation is related to a minor landslide occurred within the body of the main one nearby the eastern sector on 4 February, after a rainfall event. The evolution of this latter landslide is shown by a mosaic of incremental interferograms spanning a time interval of $2 \mathrm{~h}$ and $7 \mathrm{~min}$ (Fig. 10). On 4 February the landslide reached a maximum velocity of $38 \mathrm{~mm} \mathrm{~h}^{-1}$. This rate was estimated by averaging all the 14 interferograms of the period (20 interferograms). This proved the capability of the system to catch smaller, faster movements lasting only a few minutes. By increasing the time spanning, the interferograms (Fig. 10c-f) show a complete decorrelation on the 4 February landslide sector, while it is still possible to estimate the velocity of the top and the western sector of the landslide.

A few days later (since 6 February 2009; B in Fig. 9) a period characterized by a decrease in the deformation velocity started; successively it began a new period during which the cumulative displacement in the western sector reached values higher than $950 \mathrm{~mm}$ in 7 days (C in Fig. 9). Starting from the last week of February, the displacement velocity decreased progressively from values of about $400 \mathrm{~mm}$ in 7 days (end of February; D in Fig. 9) to values of about $45 \mathrm{~mm}$ in 7 days (mid of April; F in Fig. 9); a small acceleration (E in Fig. 9) was recorded at the end of March after an intense rainfall (cumulated rainfall in 2 days: $40 \mathrm{~mm}$ ).

\section{Discussion}

Since the main accelerating phases were preceded by precipitations, a comparison between the cumulated displacements recorded at the point P6 (chosen as representative) and the cumulated rainfall has been carried out (Fig. 11). The rainfall values were measured near Scilla, about $3.5 \mathrm{~km} \mathrm{NW}$ from the site.

The first two weeks of monitoring were characterized by almost continuous rain (more than $96 \mathrm{~mm}$ cumulated rainfall); in this period the velocity of the landslide reached $140 \mathrm{~mm} \mathrm{day}^{-1}$. Two other periods of heavy rainfall were recorded during the monitoring campaign, the first one between 4 March and 7 March (30.6 mm of cumulated rainfall in $72 \mathrm{~h}$ ) and the second one between 20 March and 22 March ( $39.6 \mathrm{~mm}$ of cumulated rainfall in $51 \mathrm{~h}$ ). The last rainstorm, although of lesser intensity $(16.4 \mathrm{~mm}$ in $36 \mathrm{~h})$, occurred between 12 April and 14 April, but seemingly did not affect the landslide (Fig. 11a).

Although few events were taken into account, the time span between precipitations and landslide acceleration seems to vary, even if, as expected from a landslide of this size and type, the delay is always quite short; during the first half of February a very short delay, lasting just few hours, is observed. After the second major rain event (4 March 7 March), 3 days were required for the landslide to undergo 

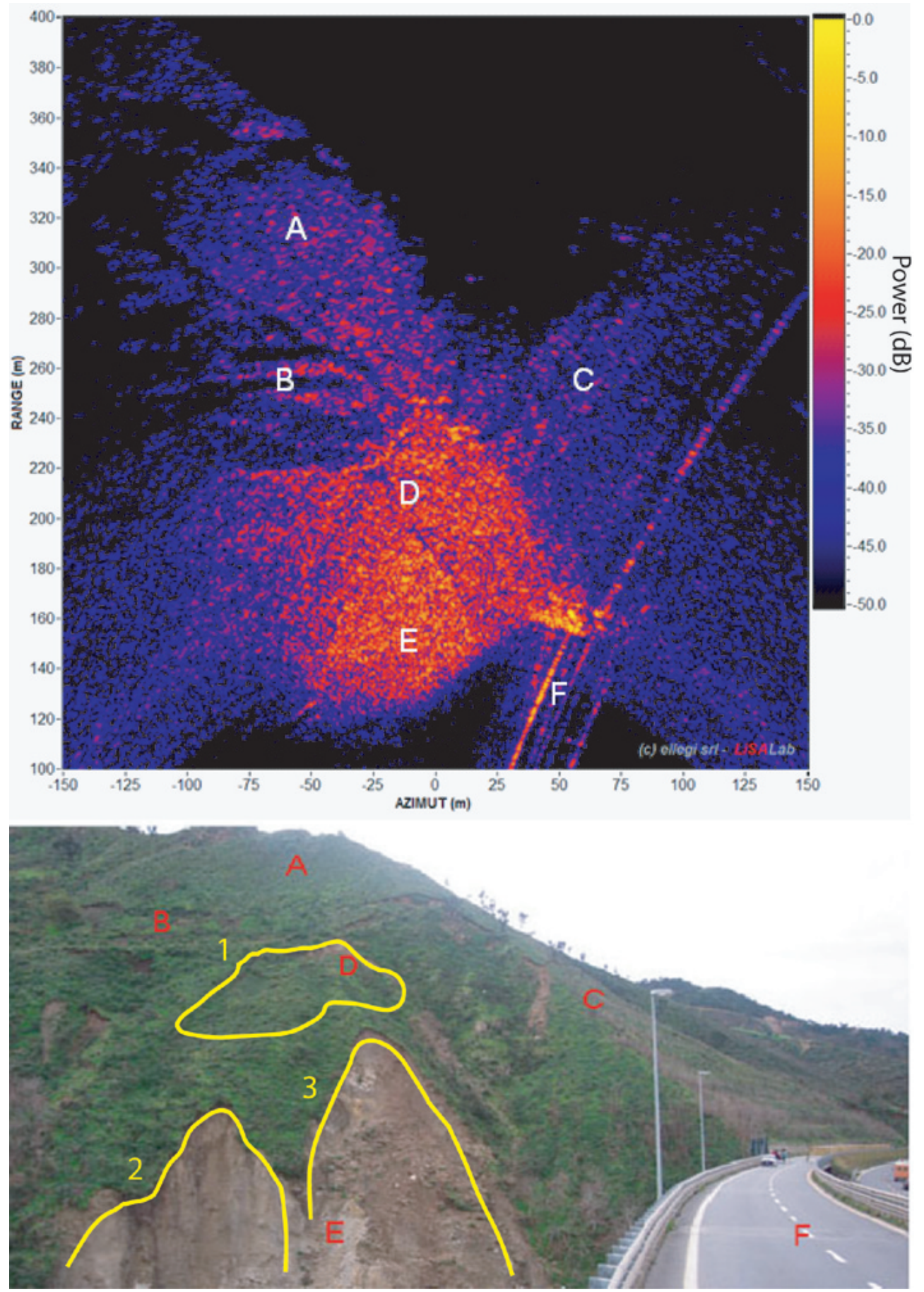

Fig. 6. Power image of Santa Trada landslide (top) compared to a photograph (bottom), both acquired from the radar position. A and B: stable areas; C: NW slope; D and E: unstable areas; F: A3 motorway. Landslide sectors: 1 - top sector; 2 - eastern sector; 3 - western sector.

an acceleration while, during the end of the March event, the deformation rate of the landslide increased after only $24 \mathrm{~h}$. A comparison between rain events and landslide kinematics shows how the slope acceleration occurs with different time lags. Furthermore, even though a close correlation between rainfall and landslide acceleration is evident, not every rain event induced a corresponding increasing in the displacement rate (as during the 12 April - 14 April event).

This can be explained considering the antecedent rainfall. In Fig. 11b the landslide cumulative displacement (point P6) 


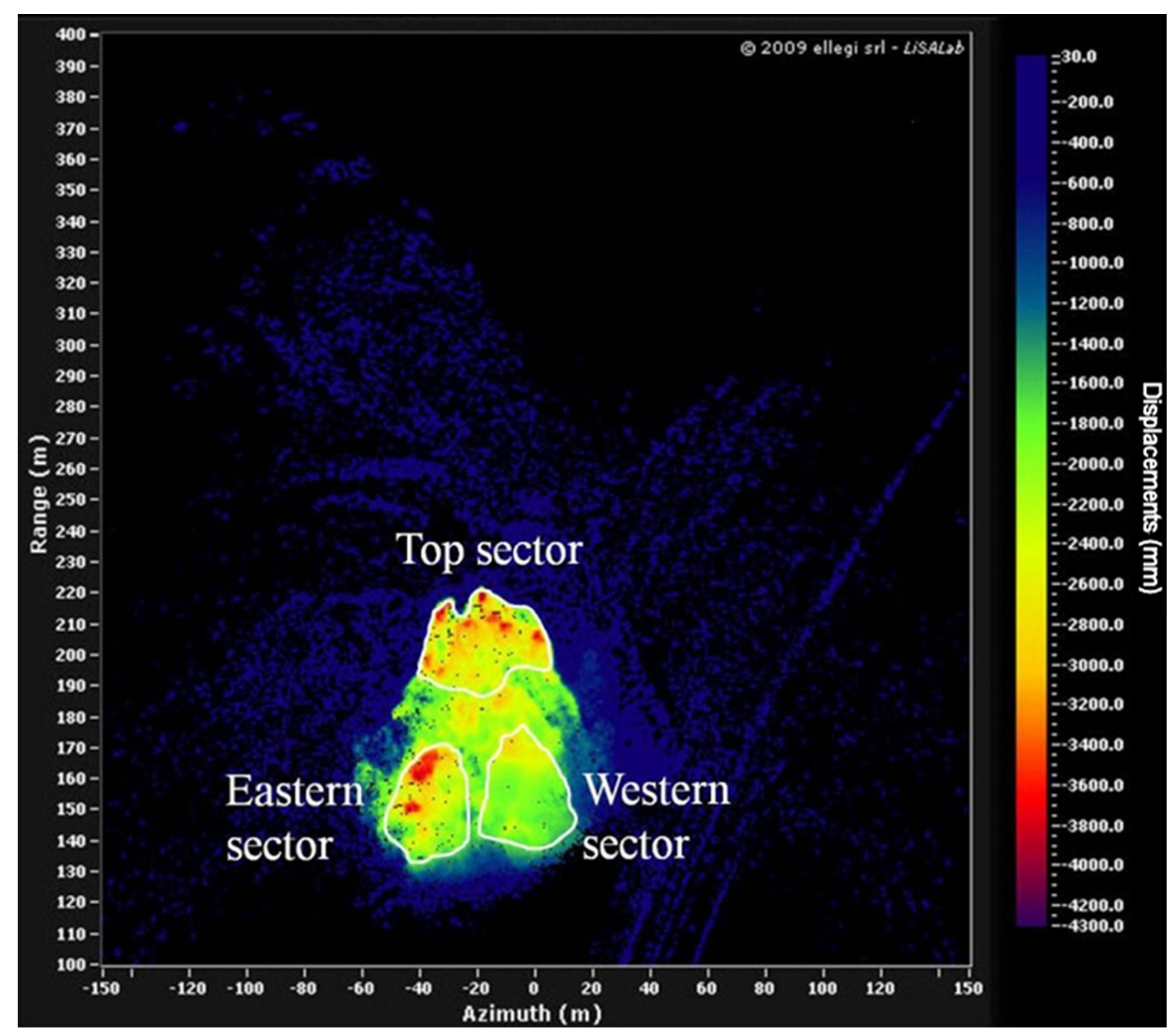

Fig. 7. Displacement map covering the entire duration of the campaign. Three different sectors are visible. The cumulative displacement recorded during the whole monitoring period of 86 days (from 2 February 2009 to 29 April 2009) reached the value of $4320 \mathrm{~mm}$.

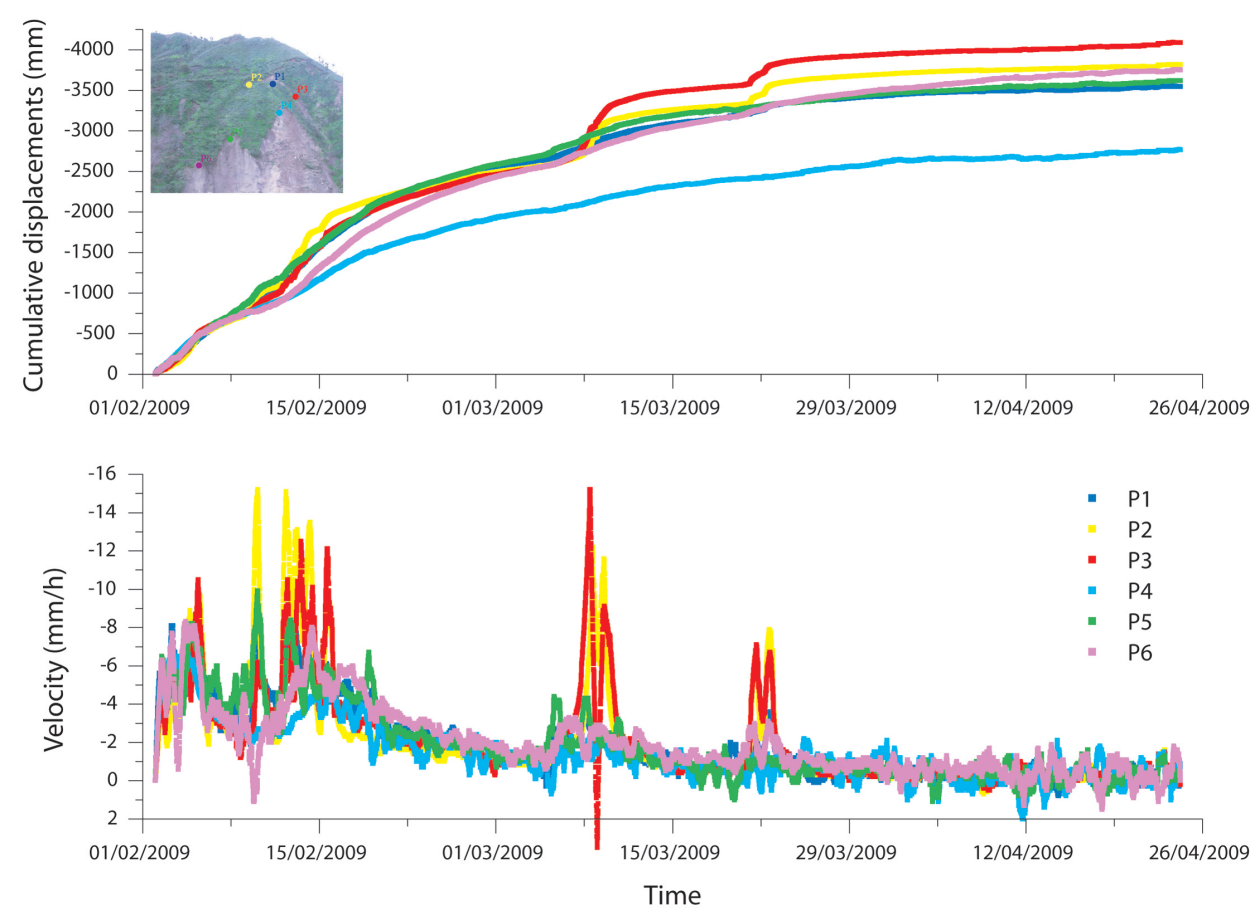

Fig. 8. Cumulative displacement versus time diagram (on the top) and velocity versus time diagram (on the botton). 

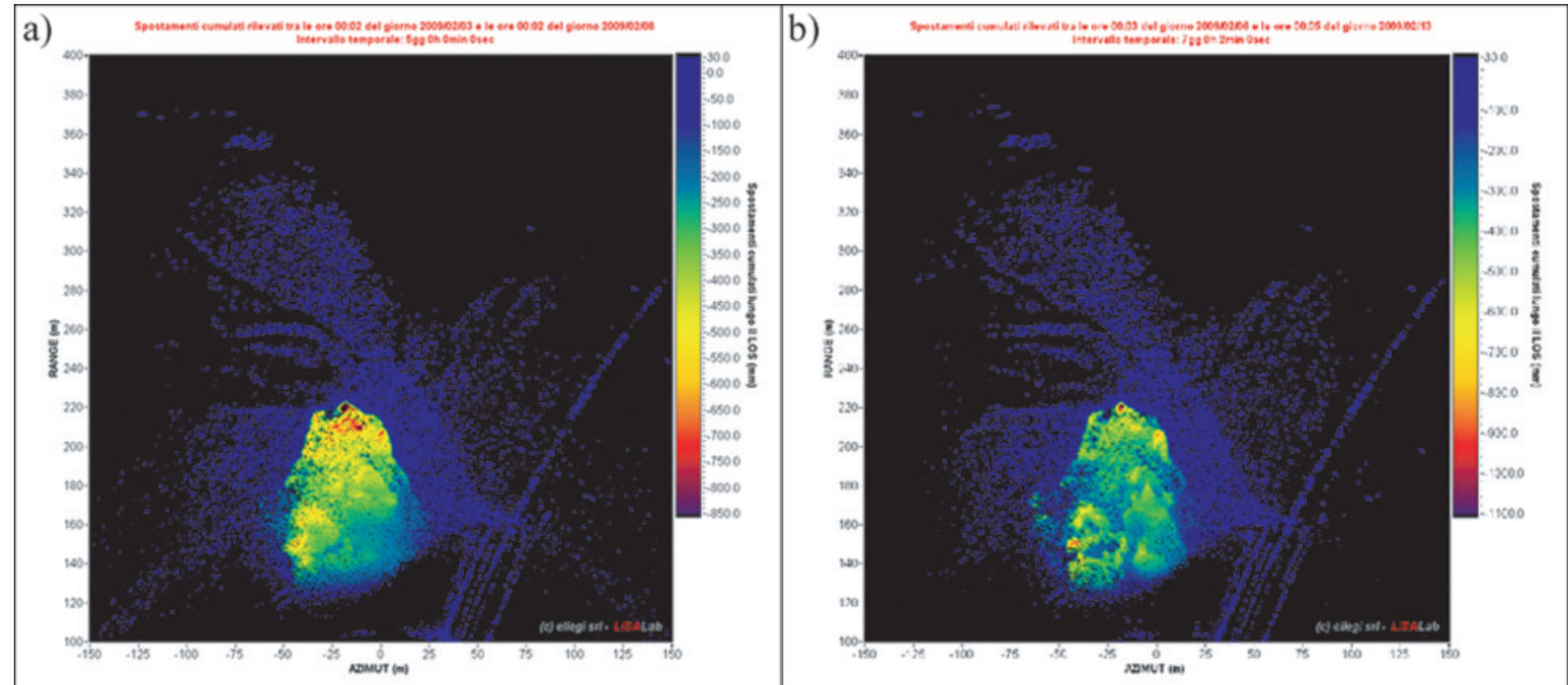

c)

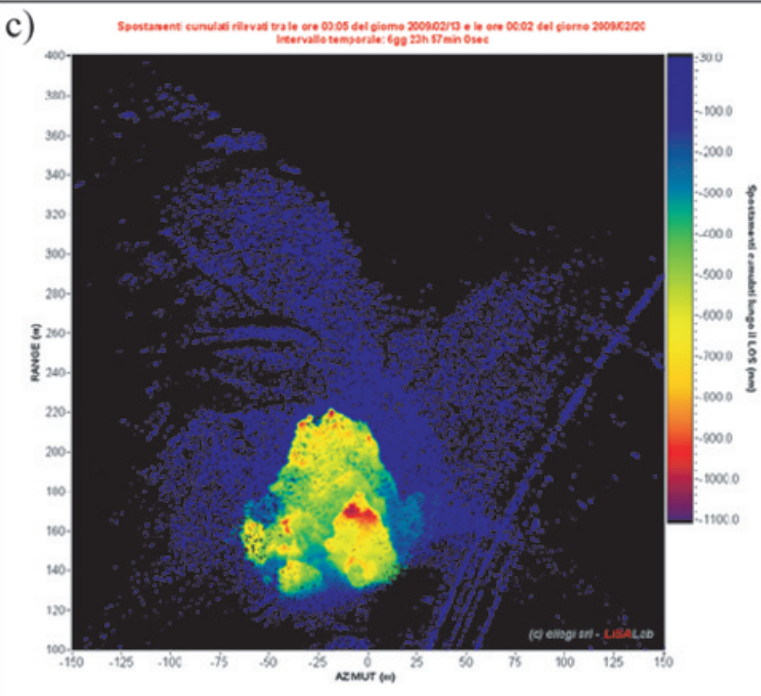

d)

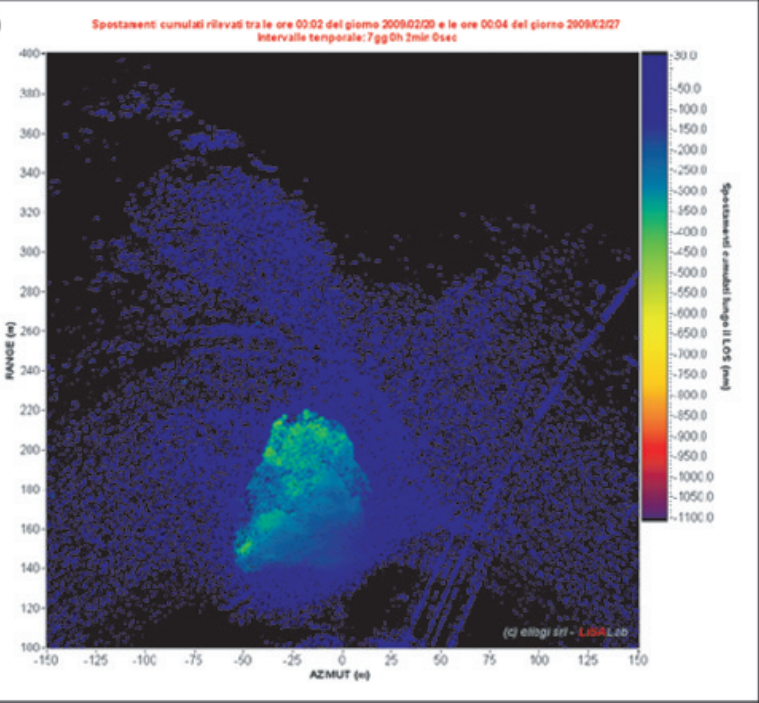

e
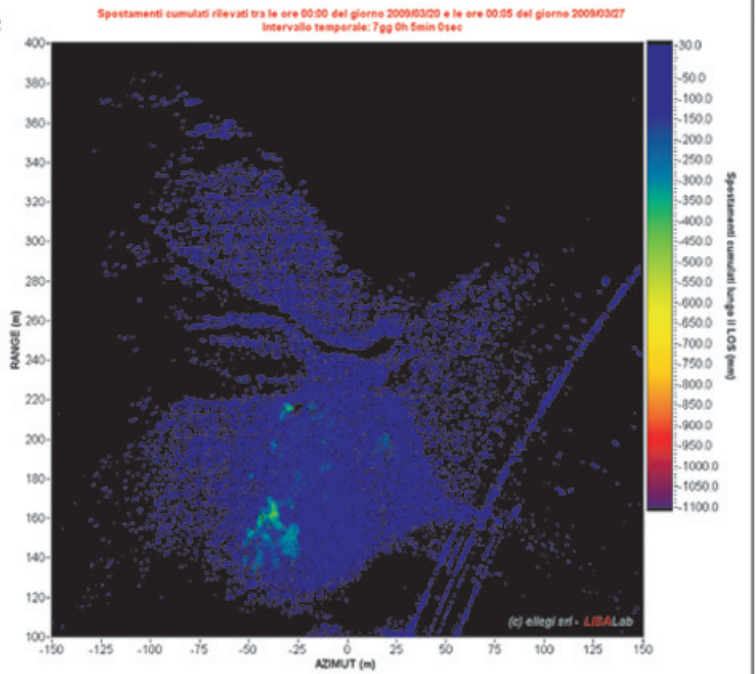

f)

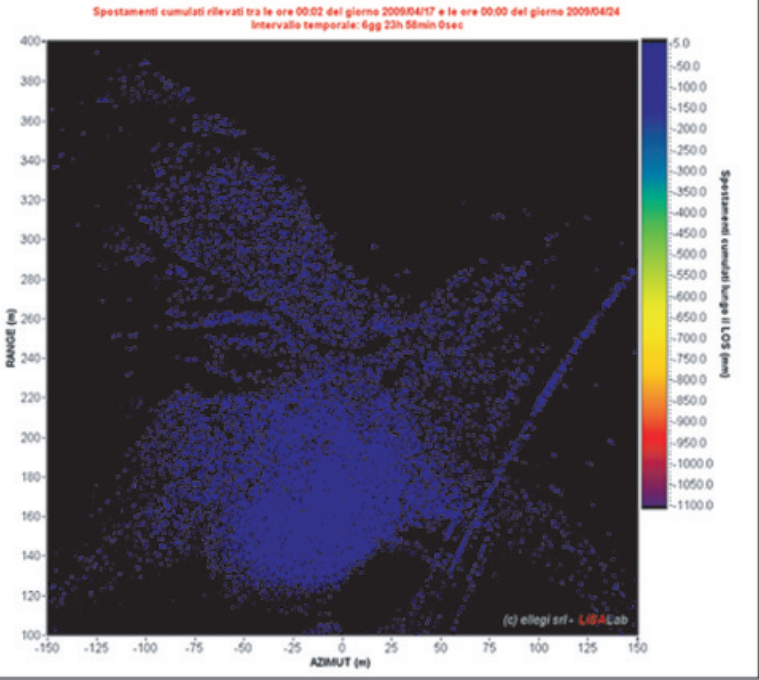

Fig. 9. Cumulative displacement maps that cover the entire time span of the monitoring campaign. The elapsed time for each of them is: (a) 02/02/09-09/02/09; (b) 06/02/09-13/02/09; (c) 13/02/09-20/02/09; (d) 20/02/09-27/02/09; (e) 20/03/09-27/03/09; (f) 17/04/09$24 / 04 / 09$. Note that the chromatic scale is not the same among all the maps. 

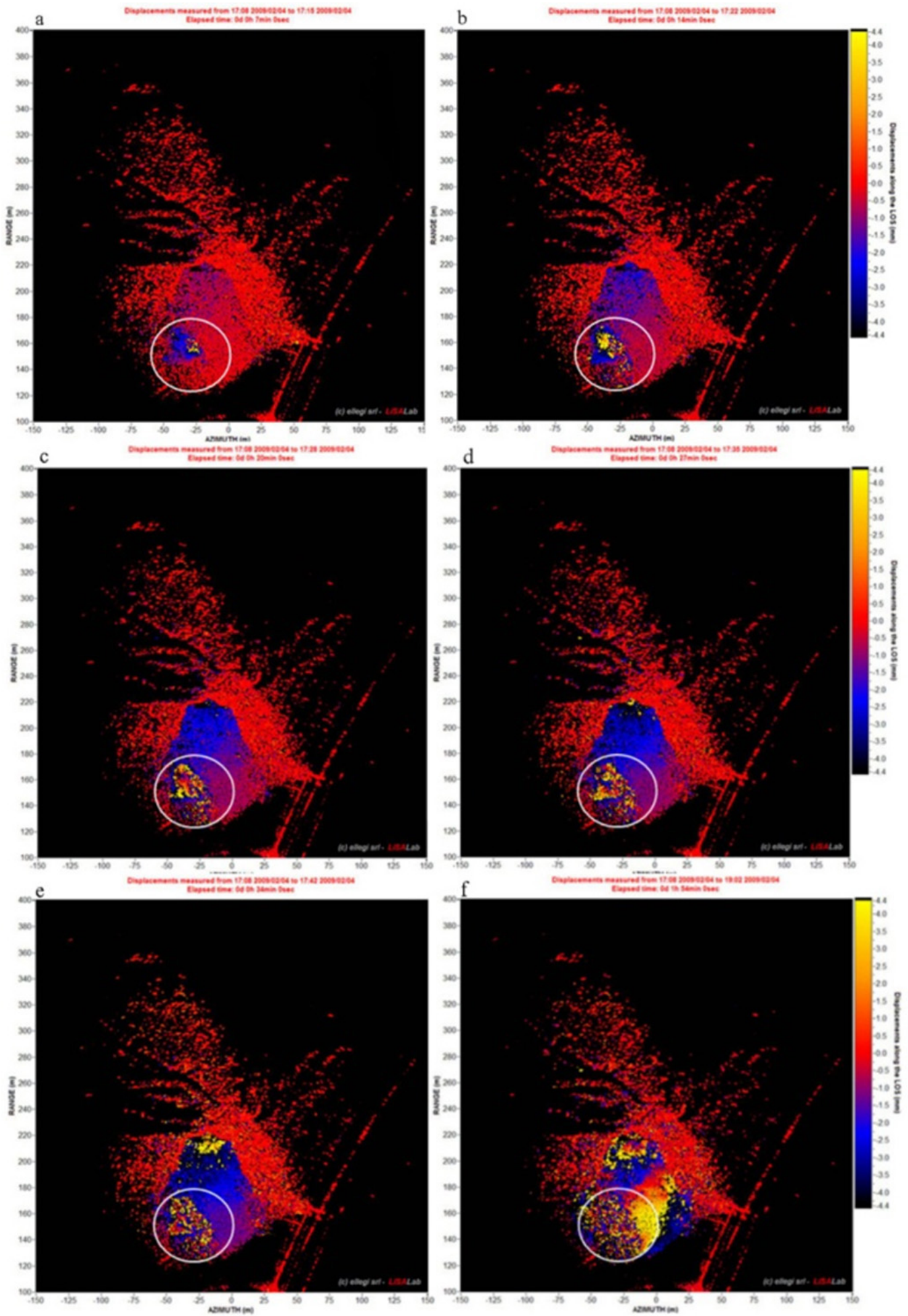

Fig. 10. Mosaic of incremental interferograms starting from 5:08 p.m. of 4 February 2009. The time intervals for each interferogram are respectively: (a) $7 \mathrm{~min}$; (b) $14 \mathrm{~min}$; (c) $20 \mathrm{~min}$; (d) $27 \mathrm{~min}$; (e) $34 \mathrm{~min}$; (f) $1 \mathrm{~h}$ and $54 \mathrm{~min}$. 

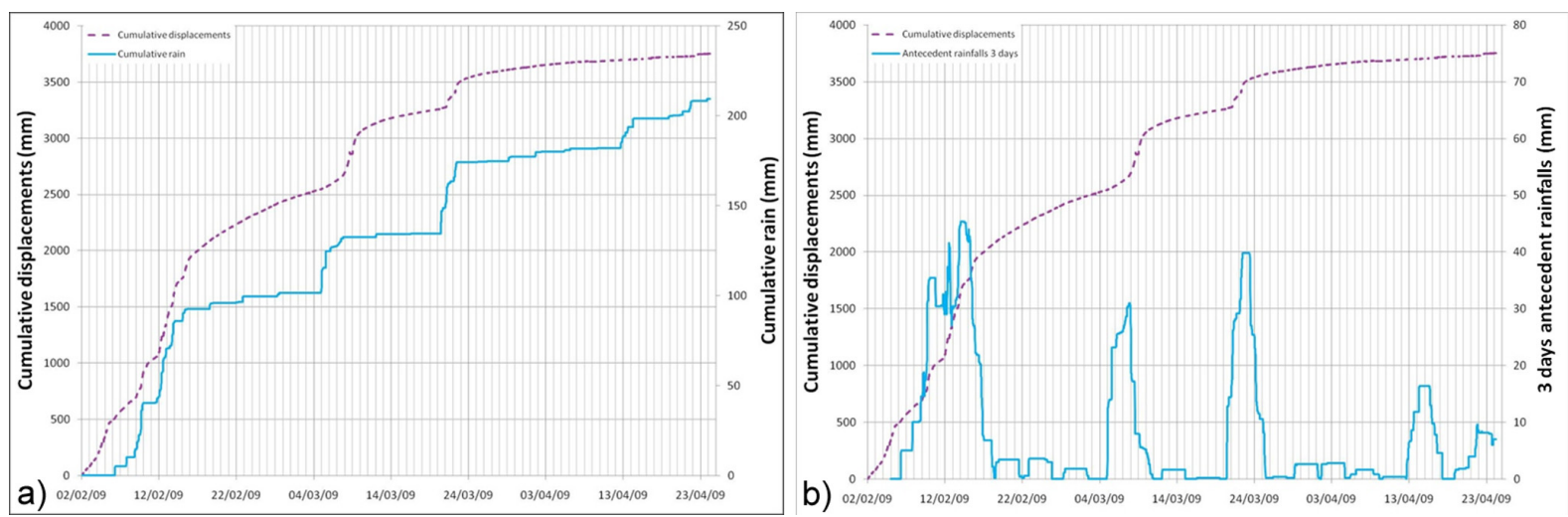

Fig. 11. (a) Comparison between the cumulative displacements of point $\mathrm{P} 6$ and cumulative rain values; (b) comparison between the cumulative displacements of point $\mathrm{P} 6$ and 3 days antecedent rainfall.

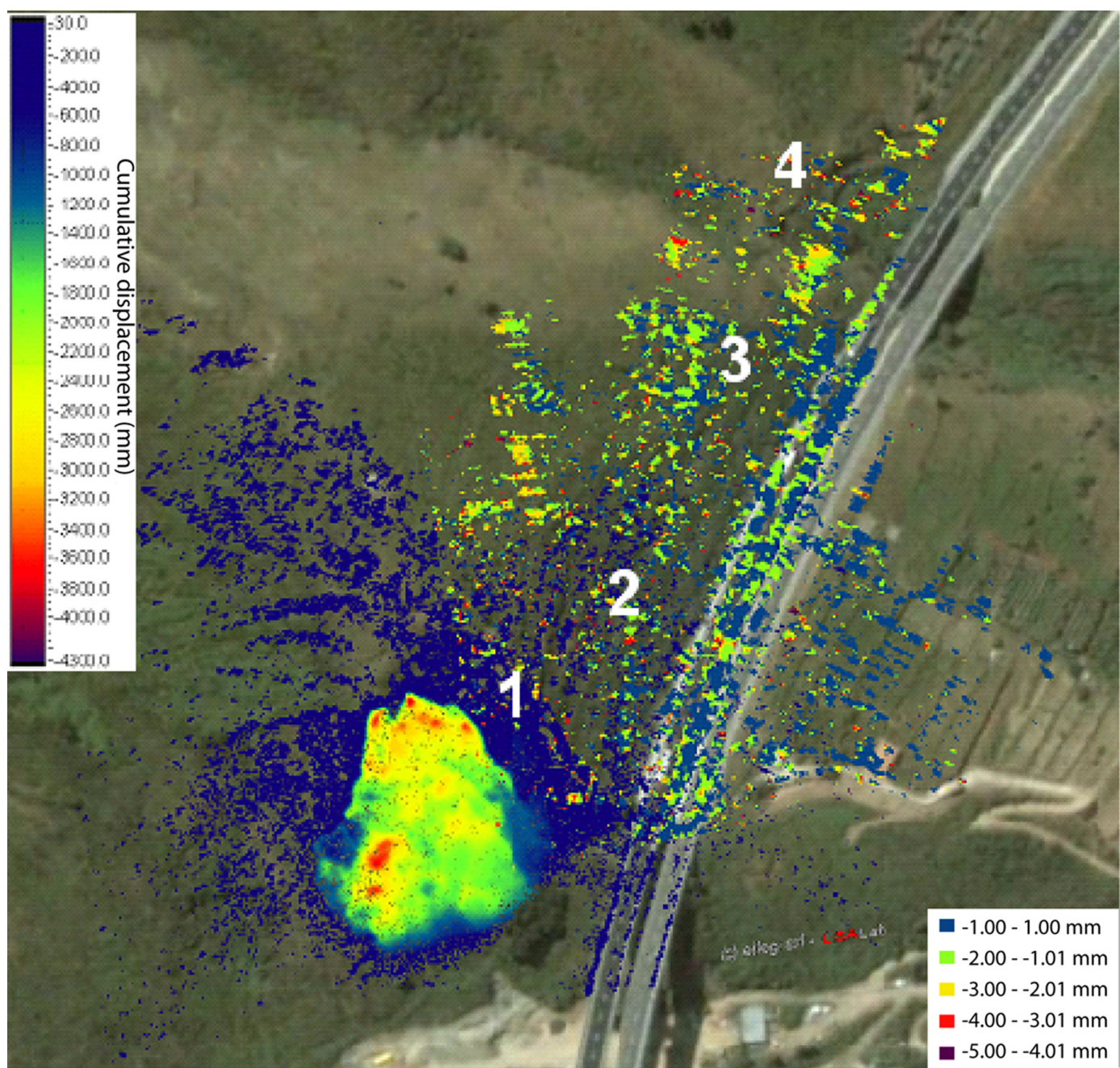

Fig. 12. Cumulated displacement map corresponding to 59 days (between 4 February and 4 April). Note that the scale bars used to represent the displacements of the two slopes are different: the scale bar on the left refers to the main slope, while the one on the bottom right refers to the NW slope. Both the scale are in mm. 
is plotted against the 3 days antecedent rainfall. By analyzing these correlations, it is possible to assess that the displacement extent is related to the rainfall duration (Fig. 11a) while the landslide acceleration delay seems to be proportional to the antecedent rainfall (Fig. 11b). Obviously, due to the brief duration of the monitoring, these observations represent a description of the landslide behavior during the monitoring period and do not represent a proposal for acceleration thresholds. As a close relationship between precipitations and displacements has been observed, a re-activation could be possibly triggered by new intense rainfalls.

During the campaign it was observed that also the contiguous slope, the one facing NW, was fractured in many points (Fig. 6 sector C). Although the thickness of the material involved in this sector is moderate (probably less than $1 \mathrm{~m}$ ), it represents a direct threat to the motorway located just in front of the slope. For this reason, an interferometric analysis was made also for this sector. Since it was not the original objective of the campaign, the alignment between the radar LOS and the assumed direction of movement of the slope was not the most favorable; this means that the displacements recorded by the GB-InSAR represent just a component (in this case a percentage between $15 \%$ and $35 \%$ ) of the displacement. A cumulative displacement map, spanning a time interval of 59 days (between 4 February and 4 April) shows a maximum cumulated displacement of about $5 \mathrm{~mm}$ (Fig. 12). The NW slope has been divided into 4 zones, the zones 3 and 4 being the ones that recorded the highest movement. Considering a total displacement of $5 \mathrm{~mm}$, an average velocity of $0.08 \mathrm{~mm} \mathrm{day}^{-1}$ can be obtained for these sectors; by performing the correction for the LOS, it results to be between $0.2 \mathrm{~mm} \mathrm{day}^{-1}$ and $0.5 \mathrm{~mm}_{\text {day }}{ }^{-1}$.

\section{Conclusions}

During December 2008 and January 2009 intense rainfall occurred in Italy, especially in the southern regions. Cumulative monthly rain values recorded near Scilla (Reggio Calabria - Calabria Region) were largely over the seasonal average and caused the saturation of soils for almost the entire period, worsening the already critical hydrogeological conditions. On 30 January 2009 a landslide occurred near Santa Trada, threatening the pillars of a viaduct of the A3 motorway. The closure of the street, imposed by the DPC, worsened an already critical situation and caused heavy economic losses. On 1 February, a GB-InSAR was installed in order to monitor the landslide and to assess possible risk scenarios. Thanks to the GB-InSAR monitoring, the motorway was re-opened on 2 February, demonstrating the full effectiveness of this system in managing landslide emergencies. It also granted the possibility of acquiring data during precipitations which represent the most critical events for slope stability. Indeed, usually traditional landslide monitoring instruments are not able to work in such conditions and to provide such useful information in real-time, since they normally require a longer time for the installation and a direct access to the unstable and unsafe sites. Thanks to the displacement maps provided by the GB-InSAR, it has been possible to delimitate the area affected by the movement and to identify some temporal phases characterized by different activity levels. Furthermore, after a few days of monitoring, two possible risk scenarios were hypothesized:

- Progressive mobilization of small shallow landslides: the landslides could obstruct a minor road present at the foot of the slope. In this case, the debris would probably not have concerned the motorway or its pillars.

- Mobilization of the whole landslide: in this case, considering the estimated volume of several tens of thousands of cubic meters, the motorway pillars could have been affected by the failure.

In addition, considering the characteristics of the material involved and the geomorphology of the area, in case of collapse of the whole landslide, an unstable dam on the Fiumara di Santa Trada could have developed.

The comparison between rainfall data and landslide accelerations demonstrated a clear influence of the rain on landslide movement. The usefulness of the GB-InSAR system was not only limited to the capability of fully characterizing the landslide in spatial terms; it also permitted the operators to follow, during the whole campaign, the evolution of the mass movement and to study its kinematic behavior, which was fundamental in order to assess the risk scenarios' temporal evolution.

In the end, this work aims at providing its own contribution within the framework of risk management (Fell et al., 2005), especially presenting an efficient approach to landslides' emergency management.

Acknowledgements. This work has been sponsored by the National Civil Protection Department (DPC), within the framework of the SAR.net Project. The DPC is acknowledged for the support of the project and for the permission given to its publication. The authors are grateful to Paolo Putrino from the DPC for making rainfall data available. The GB-InSAR apparatus has been designed and produced by the Ellegi society and is based on the proprietary technology GB-InSAR LiSALAB derived from the evolution and improvement of LiSA technology licensed by the Joint Research Centre of Ispra of the European Community. We thank D. Keefer and the anonymous reviewer for the constructive revisions which helped to improve the manuscript.

Edited by: F. Guzzetti

Reviewed by: D. Keefer and another anonymous referee 


\section{References}

Antonello, G., Casagli, N., Farina, P., Leva, D., Nico, G., Sieber, A. J., and Tarchi, D.: Ground-based SAR interferometry for monitoring mass movements, Landslides 1, 21-28, 2004.

Antonello, G., Fortuny, J., Tarchi, D., Casagli, N., Del Ventisette, C., Guerri, L., Luzi, G., Mugnai, F., and Leva, D.: Microwave interferometric sensors as a tool for space and time analysis of active volcano deformations: the Stromboli case, Proceedings of the 2008 2nd Workshop on USE of Remote Sensing Techniques for Monitoring Volcanoes and Seismogenic Areas, USEReST 2008. Second workshop on 11-14 November 2008, 1-6, 2008.

Atzeni, C., Basso, M., Canuti, P., Casagli, N., Leva, D., Luzi, G., Moretti, S., Pieraccini, M., Sieber, A. J., and Tarchi, D.: Ground-based SAR interferometry for landslide monitoring and control, ISSMGE Field Workshop on Landslides and Natural/Cultural Heritage, Trabzon (Turkey), 23-24 August 2001, 195-209, (CNR GNDCI Pub. No.2375), 2001a.

Atzeni, C., Canuti, P., and Tarchi, D.: Monitoring unstable cultural heritage sites with radar interferometry, in: UNESCO/IGCP Symposium on Landslide Risk Mitigation and Protection of Cultural and Natural Heritage, edited by: Sassa, K., Tokyo, Japan, 15-19 January 2001, 257-264, 2001b.

Barbieri, M., Corsini, A., Casagli, N., Farina, P., Coren, F., Sterzai, P., Leva, D., and Tarchi, D.: Space-borne and ground-based SAR interferometry for landslide activity analysis and monitoring in the Appennines of Emilia Romagna (Italy): review of methods and preliminary results, European Space Agency, (Special Publication) ESA SP 550, 463-470, 2004.

Barla, G., Antolini, F., Barla, M., Mensi, E., and Piovano, G.: Monitoring of the Beauregard landslide (Aosta Valley, Italy) using advanced and conventional techniques, Eng. Geol., 116, 3-4, 218235, 2010.

Casagli, N., Farina, P., Leva, D., Nico, G., and Tarchi, D.: Groundbased SAR interferometry as a tool for landslide monitoring during emergencies, Geoscience and Remote Sensing Symposium, Proceedings IGARSS '03, IEEE International 4, 2924-2926, 2003.

Casagli, N., Tibaldi, A., Merri, A., Del Ventisette, C., Apuani, T., Guerri, L., Fortuny-Guasch, J., and Tarchi, D.: Deformation of Stromboli Volcano (Italy) during the 2007 crisis by radar interferometry, numerical modeling and field structural data, J. Volcanol. Geoth. Res., 182, 182-200, 2009.

Casagli, N., Catani, F., Del Ventisette, C., and Luzi, G.: Monitoring, prediction, and early warning using ground-based radar interferometry, Landslides, doi:10.1007/s10346-010-0215-y., 2010.

Fell, R., Ho, K. K. S, Lacasse, S., and Leroi, E.: A framework for landslide risk assessment and management, edited by: Hungr, O., Fell, R., Couture, R., and Eberhardt, E., Landslide Risk Management, Taylor and Francis, London, 3-26, 2005.
Gigli, G., Fanti, R., Canuti, P., and Casagli, N.: Integration of advanced monitoring and numerical modeling techniques for the complete risk scenario analysis of rockslides: The case of Mt. Beni (Florence, Italy), Eng Geol., 120, 48-59, 2011.

Luzi, G., Pieraccini, M., Mecatti, D., Noferini, L., Guidi, G., Moia, F., and Atzeni, C.: Ground-based radar interferometry for landslides monitoring: atmospheric and instrumental decorrelation sources on experimental data, IEEE T. Geosci. Remote Sens., 42, 11, 2454-2466, 2004.

Luzi, G., Pieraccini M., Mecatti D., Noferini L., Macaluso G., Galgaro A., and Atzeni C.: Advances in ground based microwave interferometry for landslide survey: a case study, Int. J. Remote Sens., 27, 12, 2331-2350, 2006.

Marchetti, M. P.: Carta Geologica della Calabria a scala 1:25000, 1968.

Pieraccini, M., Tarchi, D., Rudolf, H., Leva, D., Luzi, G., and Atzeni, C.: Interferometric radar for remote monitoring of building deformations, Electron. Lett., 36, 6, 569-570, 2000.

Pieraccini, M., Casagli, N., Luzi, G., Tarchi, D., Mecatti, D., Noferini, L., and Atzeni, C.: Landslide monitoring by groundbased radar interferometry: a field test in Valdarno (Italy), Int. J. Remote Sens., 24, 6, 1385-1391, 2003.

Rudolf, H., Leva, D., Tarchi, D., and Sieber, A. J.: A mobile and versatile SAR system, Proc. IGARSS 99, 595-594, 1999.

Tarchi, D., Ohlmer E., and Sieber A. J.: Monitoring of Structural Changes by Radar Interferometry, Res. Nondestruct. Eval., 9, 213-225, 1997.

Tarchi, D., Nesti, G., Prati, C., and Rocca, F.: SAR interferometric techinques from ground based system for the monitoring of landslides, Proc. PIERS Workshop on Advances in Radar Methods, 230-233, 1998.

Tarchi, D., Rudolf, H., Luzi, G., Chiarantini, L., Coppo, P., and Sieber, A. J.: (SAR interferometry for structural changes detection: a demonstration test on a dem. Proc. IGARSS 99, 15221524, 1999.

Tarchi, D., Basso, M., Farina, P., Leva, D., Casagli, N., Del Piccolo, A., Moretti, S., Luzi, G., Pieraccini, M., Mannucci, G., and Tavelli, S.: Applicazione dell'interferometria radar da terra per il controllo dei movimenti franosi: la frana del Ruinon in Valfurva (SO),in: Tipografia Grifo, edited by: Canuti, P. and Sieber, A. J., Perugia, Pubblicazione CNR-GNDCI 2543, 79, 2002.

Tarchi, D., Casagli, N., Fanti, R., Leva, D., Luzi, G., Pasuto, A., Pieraccini, M., and Silvano, S.: Landslide monitoring using ground-based SAR interferometry: an example of application to the Tessina landslide in Italy, Eng. Geol., 69, 15-30, 2003. 